\title{
The results of different labour induction approaches: A Cross sectional study
}

\begin{abstract}
Background and Purpose: To evaluate the use of prostaglandins and oxytocin in labour induction according to different indications. Perinatal outcomes, rate of vaginal delivery and complation of labour were studied and compared
\end{abstract}

Methods: Cross-sectional descriptive study from January 2012 to December 2012. 530 women who required labour induction were included. Seven groups were created according to the methods of induction. Women with twin pregnancies, induction of dead foetus, two previous caesarean sections or an incomplete clinical history were excluded.

Results: The rate of vaginal deliveries in women that only received prostaglandins the first day was $84.6 \%$; similar in women with prolonged pregnancies, $85.2 \%$. The induction with oxytocin directly showed the highest rate of caesarean section. The rate of vaginal deliveries was $50 \%$ in women with previous caesarean section.

Conclusions: A high rate of vaginal deliveries with a single dose of prostaglandin and within 24 hours of beginning induction. Administration of prostaglandins must be used when cervix is unfavorable and previous to oxytocin stymulation.

Keywords: labour induction, vaginal dinoprostone, prostaglandin, oxytocin, cervical ripening and vaginal delivery
Volume 12 Issue 2 - 2021

\author{
María Dolores Lara Dominguez,' Jorge Duro \\ Gómez,' Antonio De La Torre Gonzalez,' \\ Araceli Lopez Jimenez,' Beatriz Pineda \\ Reyes,' Camil Castelo-Branco ${ }^{2}$ \\ 'Physicians specializing in obstetrics and gynecology, Spain \\ ${ }^{2}$ Clinic Institute of Gynecology, Obstetrics and Neonatology, \\ Hospital Clínic Barcelona, Head of Obstetrics \& Gynecology \\ Unit, University of Barcelona, Spain
}

Correspondence: Jorge Duro Gómez, Physicians specializing in obstetrics and gynecology, C/Arabista Joaquina Eguaras $n^{\circ} 2$ Esc 4 IB, CP I40I I Córdoba, Spain, Tel 6858I803, Email jorgedurogomez@gmail.com

Received: April 10, 2021 | Published: April 26, 2021

\section{Introduction}

Labour induction is a process of artificial stimulation of uterine contractions before the spontaneous onset of natural labour with the aim to achieve a vaginal delivery. It is one of the most common obstetric interventions, occurring in up to $30 \%$ of pregnancies. ${ }^{1-3}$ In 2004 and 2005, one in every five deliveries in the UK was induced.

The most common method of labour induction when the status of the cervix is unfavourable involves intravaginal insertion of prostaglandin, whereas when the cervix is ripe, oxytocin may be administered intravenously.,

The use of induction among nulliparous women is of particular interest, where induction is six times more likely to fail than in multiparous women..$^{7-9}$ Moreover, induced delivery could be associated with instrumental births (15\% of cases) and emergent caesarean sections ( $22 \%$ of cases). ${ }^{3,6}$

Aim of study was to know perinatal outcomes according to method used for labor induction.

\section{Materials and methods}

Cross-sectional descriptive study from January 2012 to December 2012. Our population was 530 women that required labour induction according to common, routine indications and after being informed, written consent was obtained.

There were women who were eligible for labour induction with prostaglandins, others after the second day of induction with a new dose of prostaglandins depending on the Bishop Test score, and in other cases, if the cervix had changed or was favourable within the first day or two, induction with oxytocin was performed.

We created 7 groups. Group A started the induction with $10 \mathrm{mg}$ of vaginal dinoprostone and they gave birth during that day. Group B started with $10 \mathrm{mg}$ of vaginal dinoprostone, but the second day they needed another dose of $10 \mathrm{mg}$ of vaginal dinoprostone. Group C: started with $10 \mathrm{mg}$ of vaginal dinoprostone but for 24 hours the cervix was favourable and women continued the induction with oxytocin intravenously until the childbirth. Group D started with $10 \mathrm{mg}$ of vaginal dinoprostone the first day, the second they received another dose of $10 \mathrm{mg}$ of dinoprostone, and if the cervix was favourable oxytocin was administered. Group E started with $10 \mathrm{mg}$ of vaginal dinoprostone and continued with oxytocin the second day. Group F started with $10 \mathrm{mg}$ of vaginal dinoprostone the first day, the second day they needed another dose of dinoprostone, and the third day they continued with oxytocin until the childbirth. Group G: started with oxytocin from the first day, either because the cervix was unfavourable (Bishop Score $\geq 6$ ), there was a risk of uterine hyperstimulation or because there were contraindications to administer prostaglandins.

The inclusion criteria were pregnancy with one or more of the common indications for labour induction, including post term pregnancy (41 weeks and three days in our study), premature rupture of membranes (24 hours of evolution), pre-eclampsia or higher blood pressure, oligohydramnios, hepatic cholestasis, diabetes, Intrauterine growth restriction, chorioamnionitis or causes of maternal and foetal interest.

Exclusion criteria were twin induction, induction of dead foetus, two previous caesarean sections or an incomplete clinical history.

A comparison between the different options of intervention was performed using the Chi-Square Test. In some cases, the probability of an event related to an exposure was calculated using percentages and the relative risk (RR). The SPSS 15.0 software programme was used for statistical analysis.

\section{Results}

A total of 530 women were included in the study and all of them underwent induced labour. The weeks of pregnancy were between 32 and 42 weeks, with an average of 40 weeks and a standard deviation 
of 1.6. The result of induction was: $26.4 \%$ caesarean sections, $60.9 \%$ normal deliveries and $12.6 \%$ instrumental deliveries (a total of $73.6 \%$ of vaginal deliveries). Among them, there were 308 nulliparous, 174 with previous vaginal deliveries and 48 with previous caesarean section. Table 1 shows the rate of vaginal deliveries and caesarean section according to the methods of induction. We can see in Table
2 the rate of vaginal deliveries and caesarean section according to the weeks of pregnancy. In week 39 there is a higher rate of vaginal deliveries in woman with term labour, $84.3 \%$; while with women with pre-term birth we attain $100 \%$ of vaginal delivery in week 34 and $80 \%$ in week 35 , although we have a small sample size in these weeks.

Table I The rate of vaginal deliveries and caesarean section according to the methods of induction

\begin{tabular}{llll}
\hline Different treatments & Total & Vaginal delivery & Caesarean section \\
\hline A: Prostaglandins Ist day & 234 & $198(84.6 \%)$ & $36(15.4 \%)$ \\
B: Prostaglandins Ist + 2nd day & 68 & $55(80.9 \%)$ & $13(19.1 \%)$ \\
C: Prostaglandins Ist day + Oxytocin Ist day & 10 & $8(80 \%)$ & $2(20 \%)$ \\
D: Prostaglandins Ist and 2nd day + Oxytocin 2nd day & 8 & $5(62.5 \%)$ & $3(37.5 \%)$ \\
E: Prostaglandins Ist day + Oxytocin 2nd day & 58 & $34(58.6 \%)$ & $24(4 \mid .4 \%)$ \\
F: Prostaglandins Ist and 2nd day + Oxytocin 3rd day & $13 \mid$ & $80(61.1 \%)$ & $51(38.9 \%)$ \\
G: Oxytocin Ist day & 21 & $10(47.6 \%)$ & $11(52.4 \%)$ \\
Total & 530 & 390 & 140
\end{tabular}

Table 2 The rate of vaginal deliveries and caesarean section according to the weeks of pregnancy

\begin{tabular}{lllllllllll}
\hline Weeks & $\mathbf{3 2}$ & $\mathbf{3 3}$ & $\mathbf{3 4}$ & $\mathbf{3 5}$ & $\mathbf{3 6}$ & $\mathbf{3 7}$ & $\mathbf{3 8}$ & $\mathbf{3 9}$ & $\mathbf{4 0}$ & $\mathbf{4 1}$ \\
\hline Vaginal delivery & $\mathrm{I}(50 \%)$ & $0(0 \%)$ & $6(100 \%)$ & $4(80 \%)$ & $4(66.6 \%)$ & $15(78.9 \%)$ & $52(78.7 \%)$ & $70(84.3 \%)$ & $66(70.9 \%)$ & $172(66 \%)$ \\
Caesarean section & $\mathrm{I}$ & $\mathrm{I}$ & 0 & $\mathrm{I}$ & 2 & 4 & 14 & 13 & 27 & 77 \\
Total & 2 & $\mathrm{I}$ & 6 & 5 & 6 & 19 & 66 & 83 & 93 & 249 \\
\hline
\end{tabular}

If we calculate the rate of vaginal deliveries in women treated with prostaglandins for one day as opposed to women with other treatments, we can see that the rate of vaginal deliveries in women that only received prostaglandins the first day was $84.6 \%$, whereas in women who received other types of treatment the rate was $64.9 \%$ $(\mathrm{RR}=1,3)$, that is a significant difference (Chi-Square Test 0,001$)$

When the rate of vaginal deliveries using prostaglandins two days and oxytocin the third day was calculated, the rate of vaginal deliveries was $61.1 \%$, so it was lower than the rate obtained with other treatments, which was $77.7 \%(\mathrm{RR}=1.27)$; This reduction shows a significant difference (Chi-Square Test $<0,03$ ).

We have determined the rate of vaginal delivery taking into account the reason for induction (Table 3).

We can observe that induction due to pre-labour rupture of membranes show a difference of 57 points between the rate of vaginal deliveries and the rate of caesarean section, followed by induction due to intrauterine growth restriction (a 54.6 point difference) and oligohydramnios (50.8 points). Whereas, if we divide the total of induction according to the final result, we can see that the largest percentage of vaginal deliveries is obtained when induction is indicated due to prolonged pregnancy. This is because there are more cases of induction due to prolonged pregnancy $(41.7 \%)$ compared to other causes, but it shows a difference of 40.2 points between the rate of vaginal deliveries and caesarean section.

The most frequent cause of induction is prolonged pregnancy, with 221 women. We need to turn our attention to this group in order to improve the rate of vaginal delivery. In Table 4 we show the rate of vaginal delivery in prolonged pregnancy ( 41 weeks and 3 days in our study), with $70.1 \%$ of vaginal delivery. We observe that most success is obtained in women that only received prostaglandins the first day, and the failure of the oxytocin as the only treatment.

Table 3 The rate of vaginal delivery taking into account the reason for induction

\begin{tabular}{llll}
\hline Cause of induction & Total & Vaginal delivery & Caesarean section \\
\hline Prolonged pregnancy & $221(4107 \%)$ & $155(70.1 \%)$ & $66(29.9 \%)$ \\
PRM & $158(29.8 \%)$ & $124(78.5 \%)$ & $34(21.5 \%)$ \\
Higher blood pressure & $24(4.5 \%)$ & $15(62.5 \%)$ & $9(37.5 \%)$ \\
Oligohydramnios & $65(12.3 \%)$ & $49(75.4 \%)$ & $16(24.6 \%)$ \\
Hepatic cholestasis & $7(1.3 \%)$ & $7(100 \%)$ & - \\
Intrauterine Growth Restriction & $44(8.3 \%)$ & $34(77.3 \%)$ & $10(22.7 \%)$ \\
Foetal interest & $5(0.9 \%)$ & $3(60 \%)$ & $2(40 \%)$ \\
Chorioamnionitis & $1(0.2 \%)$ & - & $1(100 \%)$ \\
Others & $5(0.9 \%)$ & $3(60 \%)$ & $2(40 \%)$ \\
\hline
\end{tabular}


Table 4 The rate of vaginal deliveries and caesarean section in prolonged pregnancies

\begin{tabular}{|c|c|c|c|}
\hline & Total & Vaginal delivery & Caesarean Section \\
\hline A: Prostaglandins I It day & & $87(85.2 \%)$ & $15(14.7 \%)$ \\
\hline B: Prostaglandins $1^{\text {st }}+2^{\text {nd }}$ day & & $20(80 \%)$ & $5(20 \%)$ \\
\hline C: Prostaglandins $I^{\text {st }}$ day + Oxytocin $\left.\right|^{\text {st }}$ day & & $3(75 \%)$ & I (25\%) \\
\hline D: Prostaglandins Ist and $2^{\text {nd }}$ day + Oxytocin $2^{\text {nd }}$ day & & $2(40 \%)$ & $3(60 \%)$ \\
\hline E: Prostaglandins $1^{\text {st }}$ day + Oxytocin $2^{\text {nd }}$ day & & $16(59.2 \%)$ & II (40.7\%) \\
\hline F: Prostaglandins $1^{\text {st }}$ and $2^{\text {nd }}$ day + Oxytocin $3^{\text {rd }}$ day & & $26(40.6 \%)$ & $28(59.3 \%)$ \\
\hline G: Oxytocin I $\left.\right|^{\text {st }}$ day & & I (25\%) & $3(75 \%)$ \\
\hline Total & 221 & $155(70.1 \%)$ & $66(29.8 \%)$ \\
\hline
\end{tabular}

We compared the vaginal delivery rate in nulliparous and multiparous women submitted to labour induction. We obtained in multiparous women; a $93.1 \%$ rate of vaginal deliveries while in nulliparous women, the rate of vaginal deliveries was $66.2 \%$. The rate of vaginal deliveries in women with previous caesarean section is low, with $50 \%$ of vaginal deliveries.

If we show the finalization of delivery in nulliparous women we can see that the rate of instrumental births is $76.1 \%$ in comparison to $23.9 \%$ observed in multiparous women $(R R=3.18)$. The same happened with the caesarean section, that was observed in $74.6 \%$ of nulliparous and in a $25.7 \%$ of multiparous women $(R R=2.9)$.

Perinatal results depend on the reason of previous caesarean section (Table 5).

We also determine the different types of induction in women with previous caesarean section. The method most frequently used was to administer prostaglandins the first day (Group A), $68.4 \%$ of vaginal deliveries were obtained. Group of treatment A and B achieved the highest rate of vaginal deliveries in women with previous caesarean section ( $68.4 \%$ and $75 \%$ respectively).

Table 5 Finalization of delivery in women with previous caesarean section

\begin{tabular}{lll}
\hline Prior caesarean section due to: & Vaginal delivery & Caesarean section \\
\hline No Progression/Failed induction I5 (31, 25\%) & 5 & 10 \\
Cephalopelvic Disproportion 7 (I4, 6\%) & 4 & 3 \\
Losing Fetal Wellbeing 9 (I8, 7\%) & 4 & 5 \\
Other causes I7 (35, 4\%) & II & 6 \\
\hline
\end{tabular}

We can observe that among cases receiving oxytocin the second day or the first day directly, as the cervix was favourable (Bishop Score $\geq 6$ ), the rate of caesarean section was greater; with $83.3 \%$ when we administered the treatment Group E, and $61.5 \%$ when we administered the treatment Group F, and $66.6 \%$ when we administered oxytocin directly without prior prostaglandin (Group G).

We determined the influence of the Bishop Test Score in the rate of vaginal deliveries. The results obtained are that if the Bishop Test Score on the first day of induction was greater than 4 , the rate of vaginal delivery was $73.8 \%$, in comparison to the $70.7 \%(R R=1.04)$ observed when the Bishop Test Score was 4 or less; although this difference was not statistically significant.

On the second day of induction, if the Bishop Test Score was greater than 4 , the rate of vaginal deliveries was $69.8 \%$, in comparison to the $63.7 \%(\mathrm{RR}=1,09)$ observed if the Bishop Test Score was 4 or less, but no significant difference was found. However, when the Bishop Test Score was calculated on the third day of induction, it was found that if the score was greater than 4 , the rate of vaginal deliveries was $81.3 \%$, but when it was 4 or less, the rate of vaginal deliveries was $45.5 \%(\mathrm{RR}=1.78)$; and that this difference was statistically significant (Chi-Square Test $<0,04)$.

Out of 530 births, it was possible to calculate postpartum $\mathrm{pH}$ in 498 cases. The average was 7.28 with a standard deviation of 0.085 ; which is within the normal range.

\section{Discussion}

Although the rate of vaginal delivery is higher than $70 \%$, in postterm labour in week 41 , the rate declines by up to $66 \%$. The rate of caesarean section in the inductions of our study was $26.4 \%$; this is acceptable taking into account other studies. In this study the rate of instrumental deliveries was $12.6 \%$ of total inductions $(17.2 \%$ of all vaginal deliveries). According to a study in the $\mathrm{UK},{ }^{3}$ labour induction is associated with $15 \%$ of instrumental births and $22 \%$ of caesarean deliveries.

According to similar studies, oxytocin without prior administration of prostaglandins is the method with the highest rate of caesarean section when women have unfavourable cervix. ${ }^{10}$ Vaginal or oral misoprostol could improve Bishop score in this patients. ${ }^{11}$ In this sense, oral misoprostol seems to have a lower rate of caesarean section. ${ }^{12}$ Moreover time to delivery is lower with oral misoprostol. ${ }^{13}$

We obtain similar results when we analyse only prolonged pregnancies, which is the main cause of labour induction. Three trials. ${ }^{11}$ including 260 women reported that oxytocin was associated with more failures in achieving vaginal delivery within 24 hours than vaginal prostaglandin E2.

In this study, we decided to treat with oxytocin directly when there was no contraindication to prostaglandins, if the cervix was considered favourable or if the Bishop Test score was 6 or more. 
However, NICE guidelines do not support the use of intravenous oxytocin alone for labour induction. In clinical practice, in the case of ruptured membranes, intravenous oxytocin is often recommended as an alternative initiating agent to prostaglandins. ${ }^{3}$ Moreover, WHO recommends that when prostaglandins are not available, intravenous oxytocin alone should be used for labour induction. ${ }^{14}$ Both guidelines acknowledge that there is a higher chance of vaginal birth within 24 hours with the use of prostaglandins as opposed to oxytocin alone.

A different group is women with premature rupture of membranes. In a systematic review ${ }^{15}$ was included 240 women that compared oxytocin to vaginal prostaglandin E2 for premature rupture of membranes at term; in this study, oxytocin was associated with a significantly shorter time from induction to delivery $(3.4+/-1.5$ versus $9.6+/-4.7$ hours; $p=0.02$ ). In our study there was no difference in the risk of caesarean section.

In our study, the induction in nulliparous women was more frequent than in multiparous, with a rate of $58.1 \%$ and $32.8 \%$ respectively $(\mathrm{RR}=1.77)$. In the case of previous caesarean delivery, the rate was only $9.1 \%$ of total labour inductions. There are other studies that conclude that labour induction in nulliparous with unfavourable cervix results in high caesarean delivery rates. ${ }^{16,17}$

It is necessary to emphasize that the efficacy of prostaglandins (dinoprostone) is also demonstrated in cases of previous caesarean section, obtaining high rates of vaginal deliveries, such as $68.4 \%$ in cases of prostaglandins for the first day, $75 \%$ in cases of prostaglandins for the first and second days, and $100 \%$ when prostaglandins and oxytocin were received the first day. However, it should be recognized that the sample is very unrepresentative.

In women with Bishop score $<7$ mechanical methods could also be helpful. Double balloon catheter or Foley cather are safe and decrease the rate of unfovourable cervix. ${ }^{18,19}$

It could be interesting to know which the cost associatted to labour induction are. According to some studies misoprostol decrease time to delivery and for this reason the cost comparated with double balloon catheher or dinoprostone is lower.

We acknowledge the limitations of the study, such as the wide range of gestation weeks and the induction in different types of pregnancies, such as prolonged pregnancies, preterm rupture of membranes and preeclampsia, among others, that are all complicated pregnancies.

\section{Acknowledgments}

Reina Sofia Maternity and Child Hospital.

\section{Funding}

None.

\section{Conflicts of interest}

The authors report no declarations of interest.

\section{References}

1. Peng CT, Siti AD, Siti ZO. Concurrent dinoprostone and oxytocin for labor induction in term premature rupture of membranes: A randomized controlled trial. Obstet Gynecol. 2009;113(5):1059-1065.

2. Prager M, Eneroth-Grimfors E, Edlund M, et al. A randomised controlled trial of intravaginal dinoprostone, intravaginal misoprostol and transcervical balloon catheter for labour induction. BJOG 2008; 115:1443-1450
3. Talaulikar VS, Arulkumaran S. Failed induction of labor: strategies to improve the success rates. Obstet Gynecol Surv. 2011;66(11):717-728.

4. Calder AA, Loughney $\mathrm{AD}$, Weir $\mathrm{CJ}$, et al. Induction of labour in nulliparous and multiparous women: a UK, multicentre, open-label study of intravaginal misoprostol in comparison with dinoprostone. BJOG. 2008;115:1279-1288.

5. Souza ASR, Amorim MMR, Feitosab FEL. Comparison of sublingual versus vaginal misoprostol for the induction of labour: a systematic review. BJOG. 2008;115:1340-1349.

6. NICE clinical guidelines 70. Induction of labour. NICE inherited clinical guideline D; 2008.

7. Ee MK, Lynn S, Lesley McC. Induction of labour: A comparison between controlled-release dinoprostone vaginal pessary (Cervidil $\left.{ }^{\circledR}\right)$ and dinoprostone intravaginal gel (Prostin E2®). Aust N Z J Obstet Gynaecol. 2008;48(5):473-437.

8. Patterson JA, Roberts CL, Ford JB, et al. Trends and outcomes of induction of labour among nullipara at term. Aust N Z J Obstet Gynaecol. 2011;51(6):510-517.

9. Pennell CE, Henderson JJ, O’Neill MJ, et al. Induction of labour in nulliparous women with an unfavourable cervix: a randomised controlled trial comparing double and single balloon catheters and PGE2 gel. BJOG. 2009;116:1443-1452.

10. Nooh A. Is it worth inducing labour in women with a previous caesarean delivery?. J Obstet Gynaecol. 2012;32(2):141-144

11. Pourali L, Saghafi N, Eslami Hasan Abadi S, et al. Induction of labour in term premature rupture of membranes; oxytocin versus sublingual misoprostol; a randomised clinical trial. J Obstet Gynaecol. 2018;38(2):167-171.

12. Chen W, Xue J, Peprah MK, et al. A systematic review and network meta-analysis comparing the use of Foley catheters, misoprostol, and dinoprostone for cervical ripening in the induction of labour. BJOG. 2016;123(3):346-354.

13. Handal-Orefice RC, Friedman AM, Chouinard SM, et al. Oral or vaginal misoprostol for labor induction and cesarean delivery risk. Obstet Gynecol. 2019;134(1):10-16.

14. WHO recommendations for induction of labour. World Health Organization; 2011.

15. Mozurkewich EL, Chilimigras JL, Berman DR, et al. Methods of induction of labour: a systematic review. BMC Pregnancy and Childbirth. 2011;11:84

16. Longino AV. Instrumental birth rate in Spain. Prog Obstet Ginecol. 2009;52(10):609-615

17. Petrou S, Taher SE, Abangma G, et al. Cost-effectiveness analysis of prostaglandin E2 gel for the induction of labour at term. BJOG. 2011;118:726-734.

18. Diederen M, Gommers J, Wilkinson C, et al. Safety of the balloon catheter for cervical ripening in outpatient care: complications during the period from insertion to expulsion of a balloon catheter in the process of labour induction: a systematic review. BJOG. 2018;125(9):1086-1095.

19. Duro-Gómez J, Garrido-Oyarzún MF, Rodríguez-Marín AB, et al. Efficacy and safety of misoprostol, dinoprostone and Cook's balloon for labour induction in women with foetal growth restriction at term. Arch Gynecol Obstet. 2017;296(4):777-781. 